\title{
Comparison of five bioassay techniques for assessing sediment-bound contaminants
}

\author{
Wolfgang Ahlf, Wolfgang Calmano, Judith Erhard \& Ulrich Förstner \\ Technische Universität Hamburg-Harburg, D-2100 Hamburg 90, F.R.G.
}

Key words: Acute bioassays, sediment, contaminants

\begin{abstract}
Biological response could not be predicted based on chemical concentration of the sediment contaminants. Bioassays integrate the response of test organisms to contaminants and nutrients. Comparative results of five acute bioassays indicated that Neubauer phytoassay was the most sensitive. The microbial biomass and algal growth tests indicated a response to the availability of contaminants and nutrients. These results suggest the usefulness of a diversity of bioassays in toxicity testing of sediment contamination.
\end{abstract}

\section{Introduction}

Many pollutants are preferentially associated with sediments in aquatic systems. Although chemical analyses provide valuable supplementary information they cannot replace direct bioassay measurements in establishing sediment quality criteria for contaminated sediments.

Environmental hazard assessments require rapid, inexpensive screening tests to characterize the extent of contamination. Preference should be given to short-term tests which are simple and reproducible. The major advantage of this approach is that the biological response to a complex mixture of compounds integrates the effects of environmental variables such as solubility, $\mathrm{pH}$, antagonism and synergism, all of which affect toxicity to organisms (Dutka \& Bitton, 1986; Munawar \& Munawar, 1987).
The comparability of bioassays is somewhat limited by the different sensitivities of test organisms to individual contaminants (Williams et al., 1986). The biological response depends on the metabolic activity of the organisms and is closely tied to the availability of contaminants from sediments.

Algal assays have proven to be very sensitive indicators of contaminant stress (Miller et al., 1985). Experimental difficulties arise from the need to provide an interacting system of sediments and algae, while retaining the ability to analyze each system separately. An approach to overcome these problems was made by Ahlf (1985), who used an apparatus in which a membrane separated the algae and sediments. The objective of our study was to compare this algal assay with four sediment bioassays using bacteria, algae and higher plants as indicators. 


\section{Materials and methods}

\section{Sediments}

Three different sediments from the Hamburg area were used for the investigations. The sediments were freeze-dried, sifted through a 2-mm sieve, and adjusted with $\mathrm{H}_{2} \mathrm{O}$ to $60 \%$ of the maximum water holding capacity. Heavy metals were analyzed using flame and carbon furnace atomic absorption spectrometry (ZAAS, Hitachi model 180-70 (Table 1). Sediment samples were Soxhlet extracted for $16 \mathrm{~h}$ with $1: 1(\mathrm{v} / \mathrm{v})$ acetone-hexane, preconcentrated and selected organochlorine compound concentrations were determined by GC (Lohse, 1988).

\section{Biological methods}

There are numerous methods available for assessing the environmental impact of sediment-associated contaminants (Ahlf \& Munawar, 1988). We used the following assays.

a) Elutriate bioassays were initially designed for monitoring of dredging projects (Keeley \& Engler, 1974). For each sediment sample an elutriate was prepared by mixing one volume of

Table 1. Measured chemical characteristics of sediments used.

\begin{tabular}{lcccc}
\hline & $\begin{array}{c}\text { Sediment } \\
\text { I }\end{array}$ & $\begin{array}{c}\text { Sediment } \\
\text { II }\end{array}$ & $\begin{array}{c}\text { Sediment } \\
\text { III }\end{array}$ & \\
\hline $\mathrm{As}$ & 11 & 45 & 5 & $(\mathrm{mg} / \mathrm{kg})$ \\
$\mathrm{Cd}$ & 6.1 & 10.4 & 0.7 & \\
$\mathrm{Cu}$ & 172 & 191 & 27 & \\
$\mathrm{Hg}$ & 1.5 & 11 & $<0.1$ & \\
$\mathrm{~Pb}$ & 457 & 172 & 61 & \\
$\mathrm{Ni}$ & 30 & 83 & 6 & \\
$\mathrm{Zn}$ & 1208 & 1178 & 127 & \\
& & & & $(\mu \mathrm{g} / \mathrm{kg})$ \\
$\mathrm{Heptachlor}-$ & & & & \\
Expoxid & 37 & 109 & $<2$ & \\
DDT & 68 & 10 & $<2$ & \\
DDT & 27 & 86 & $<2$ & \\
PCB's & 738000 & 170000 & $<5$ & \\
\hline
\end{tabular}

sediment with four volumes of test medium described by Miller et al. (1978). The mixture was agitated 30 minutes by air, settled for one hour and then passed through a $0.45 \mu \mathrm{m}$ membrane. The short-term impacts of sediment elutriates were assayed with the alga Ankistrodesmus bibraianus, using techniques developed by Miller et al. (1978).

b) While this elutriate test simulates the immediate impact of resuspended sediments on the water column, the recirculating systems (Hoke \& Prater, 1980) determine to which extent the contaminants are available within a certain period of time and how they affect the test organisms. Similarly, the exchange between the water/organism and sediment compartments can be studied in a two-chambered device in which a $0.45 \mu \mathrm{m}$ pore diameter membrane separated the algae and sediment (Ahlf, 1985). This method allowed an interaction of contaminants and algae, but prevented mixing of the algae and sediments. The inoculum contained $5 \times 10^{5}$ cells $\times \mathrm{ml}^{-1}$ of A. bibraianus. The incubation period was $72 \mathrm{~h}$.

c) The reactions of the microbial biomass were described with DNA content. The method applied has been described by Benndorf et al. (1977) for the measurement of DNA.

d) A second series of experiments were conducted in order to evaluate the bioactivity of microorganisms. For each measurement $0.5 \mathrm{~g}$ wet sediment was used. The method for determining dehydrogenase activity was described by Liu \& Strachan (1981).

e) The Neubauer phytoassay has been used to evaluate seed germination and initial plant growth of Lolium multiflorum and Lepidium sativum (Thomas \& Cline, 1985). The sediments were progressively diluted by mixing of contaminated material with washed silica sand or an uncontaminated humic sediment $(20 \%$ org. C).

All experiments were conducted in triplicate.

\section{Results and discussion}

Algal toxicity has been monitored using both sediment elutriates and sediment suspensions. 


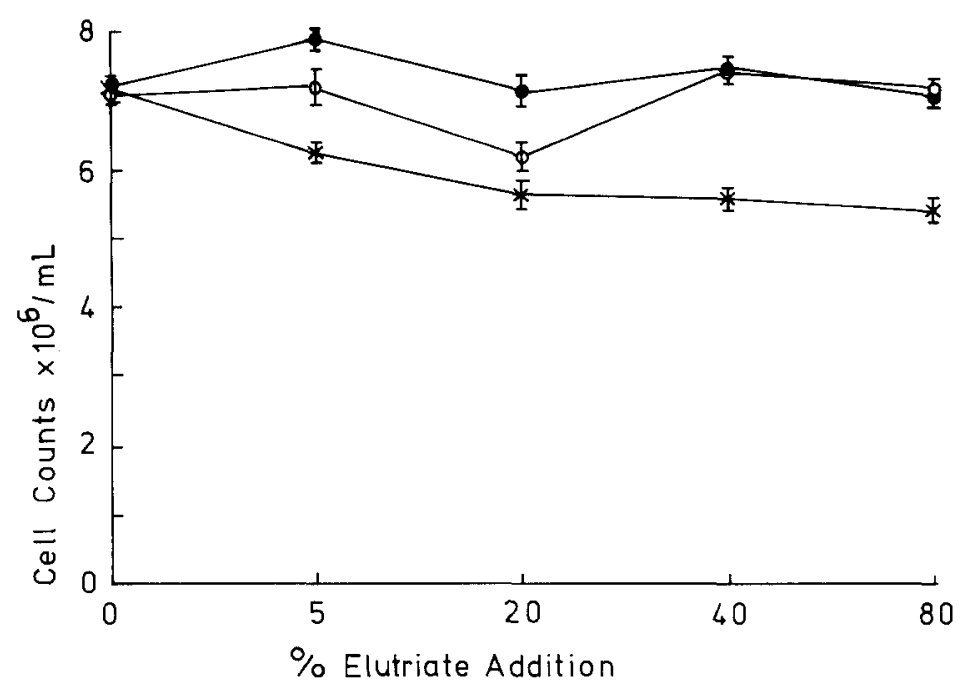

Fig. 1. Effect of standard elutriate addition on the growth of Ankistrodesmus bibraianus; bars represent the s.e.m. $\bullet=$ Sediment 1 , $0=$ Sediment $2, x=$ Sediment 3.

Increasing additions of the standard elutriate to test medium resulted in a slight inhibition of biomass production only with the Sediment 3 elutriate (Fig. 1). A more differentiated interpretation was possible with the data of the twochamber device (Fig. 2). Once again Sediment 3 affected negatively the biomass production. The addition of Sediment 1 showed a slight increase of algae growth, whereas Sediment 2 stimulated

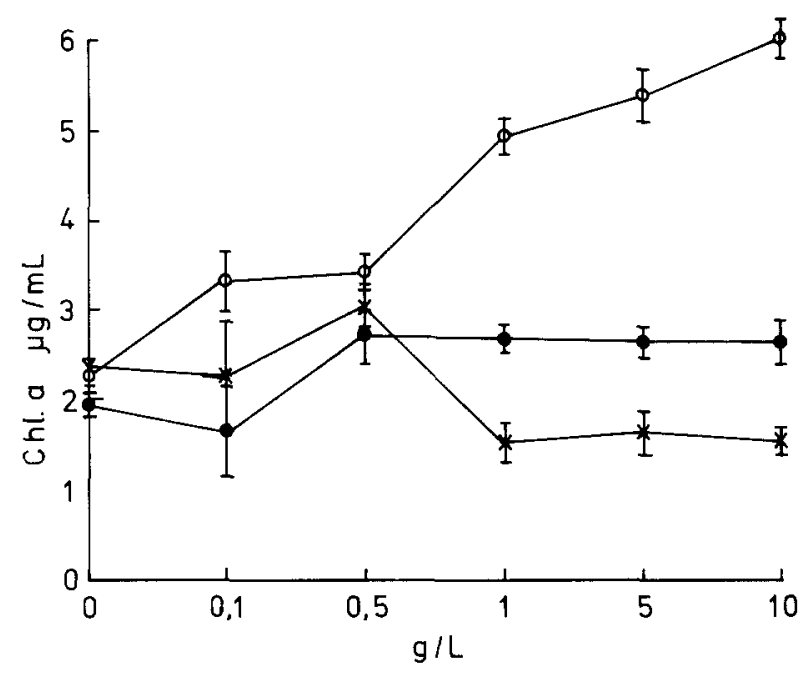

Fig. 2. Effect of sediment addition (dry weight) on the growth of $A$. bibraianus; bars represent the s.e.m. $\bullet=$ Sediment $1,0=$ Sediment $2, \mathrm{x}=$ Sediment 3 . growth of algae with increasing sediment concentration.

Mobilization of nutrients resulted in a significant enhancement of biomass compared to elutriates. The test system allowed a continous leaching during the exposure time, which seemed to be more sensitive in characterization of biological effects. The large number of chemicals associated with suspended sediments implies that water extraction alone is insufficient to detect toxic chemicals in aquatic systems (Ongley et al., 1988). The use of sediments themselves in bioassays with algae is recommended over elutriates prepared from sediments.

Direct effects of sediments on microbial biomass were conducted by estimation of DNA content after an exposure time of 6 days. Contaminants existed on sediments but did not produce a toxic response in bacteria comparable to chemical analysis (Fig. 3). The ranking of sediments by DNA content were in good agreement with the results from the two-chamber device. Additional studies on the dehydrogenase activity in sediments were performed by mixing subsamples with the artificial electron acceptor INT. However, the extracts of sediment 1 and 2 were coloured and disturbed the background control data. The estimation of dehydrogenase activities are considered 


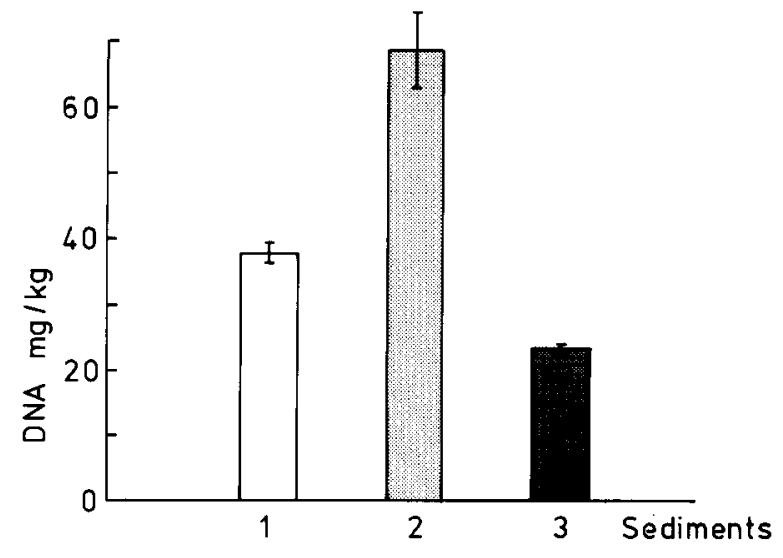

Fig. 3. DNA content in sediments after 6 days exposure time; bars represent the s.e.m.

to be an inappropriate tool for toxicity measurements in our sediment subsamples.

The Neubauer phytoassays with higher plants showed that Sediment 1 and 2 caused significant inhibition of growth. The effects of contaminated sediment were modified by the additions of humic soil or silica sand. In a sediment with high organic matter content differences to the uncontaminated control were lower than in sediments with silica sand additions. The test organisms were able to detect the presence of toxic contaminants even in dilute mixtures (Ahlf, 1988). However, data for a single biological end point (fresh weight after 10 days growth) were sufficient to demonstrate toxic effects (Fig. 4).

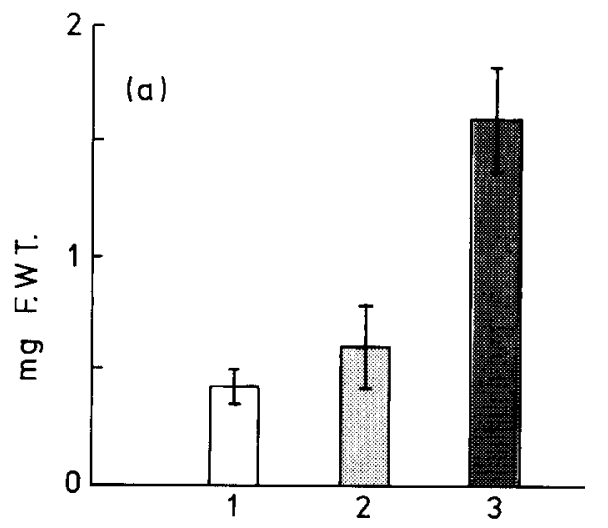

These results suggest that a soil contact phytoassay could be the most sensitive bioassay among the five techniques studied. However, Marschner et al. (1986) demonstrated that roots decreased $\mathrm{pH}$ in the rhizosphere to a $\mathrm{pH}$-value of 4-5. We believe that this particular mechanism for the mobilization of mineral nutrients is also important for the mobilization of heavy metals from Sediments 1 and 2. Thus, the toxic response of higher plants in our experiments does not reflect the entire range of all other possible contaminants. This interpretation is supported by data from former studies with algae, where the effect of decreasing $\mathrm{pH}$ was simulated in the two-chamber device under controlled conditions. A sediment, which stimulates algal growth at pH 7-8, caused high toxic response at pH 5-6 within the algae/water/suspended sediment system (Ahlf, 1985).

\section{Acknowledgment}

P. M. Chapman (E.V.S. Consultants) and an anonymous referee reviewed the manuscript and provided many helpful comments, and Dr. M. Munawar (Fisheries \& Oceans Canada) provided editorial advice.

$$
\text { Sediments }
$$

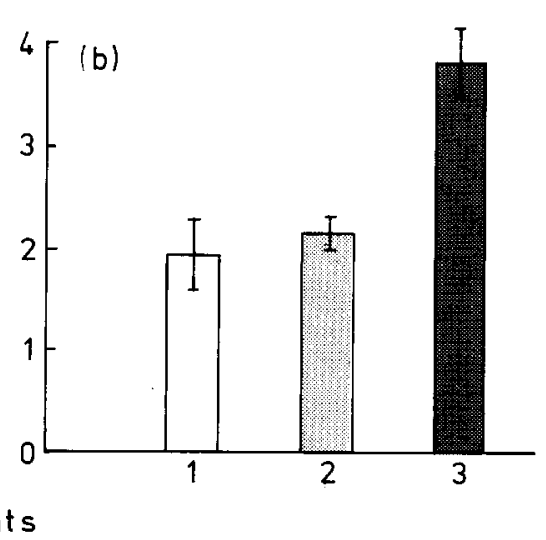

Fig. 4. Fresh weight production of Lepidum sativum (a) and Lolium multiflorum (b) grown in sediments for 10 days; bars represent the s.e.m. 


\section{References}

Ahlf, W., 1985. Behaviour of sediment-bound heavy metals in a bioassay with algae: Bioaccumulation and toxicity. Vom Wasser 65: 183-188.

Ahlf, W., 1988. Correlations between chemical and biological evaluation procedures for the determination of heavy metal availability from soils. In: K. Wolf, W. J. van den Brink \& F. J. Colon (Eds.), Contaminated Soil '88 pp. 67-69. Kluwer Academic Publishers Dordrecht.

Ahlf, W. \& M. Munawar, 1988. Biological assessment of environmental impact of dredged material. In: W. Salomons \& U. Förstner (Eds.), Chemistry and Biology of Solid Waste, pp. 127-142. Springer Verlag, Heidelberg.

Benndorf, A., J. Benndorf, W. Horn \& W. Stelzer, 1977. Biochemische Charakteristika des Sestons. Acta Hydrochim. Hydrobiol. 5: 33-42.

Dutka, B. J. \& G. Bitton, 1986 (Eds.). Toxicity Testing Using Microorganisms. Vol. 2 CRC Press, Boca Raton, Fla. pp. 186.

Hoke, R. A. \& B. L. Prater, 1980. Relationship of percent mortality of four species of aquatic biota from 96-hour sediment bioassays of five Lake Michigan harbors and elutriate chemistry of the sediments. Bull. envir. Contam. Toxicol. 25: 394-399.

Keeley, J. W. \& R. M. Engler, 1974. Discussion of regulatory criteria for ocean disposal of dredged materials; Elutriate test rationale and implementation guidelines. U.S. Army Corps of Engineers, DMRP, Vicksburg, Miss. Technical Report D-74-14. pp. 39.

Liu, D. \& G. W. Strachan, 1981. A field method for determining the chemical and biological activity of sediments. Wat. Res. 15: 353-359.
Lohse, J., 1988. Ocean incineration of toxic wastes: A footprint in North Sea sediments. Mar. Pollut. Bull. 19 (8): 366-371.

Marshner, H., V. Römheld, W. J. Horst \& P. Martin, 1986. Root-induced changes in the rhizosphere: Importance for the mineral nutrition of plants. Z. Pflanzenernaehr. Bodenk. 149: 441-456.

Miller, W. E., J. C. Greene \& T. Shiroyama, 1978. The Selenastrum capricornutum Printz. algal assay bottle test: Experimental design application, and data interpretation protocol. EPA 600/9-78-018, U.S. Environmental Protection Agency, Corvallis OR.

Miller, W. E., S. A. Peterson, J. C. Greene \& C. A. Callahan, 1985. Comparative toxicology of laboratory organisms for assessing hazardous waste sites. J. Envir. Qual. 14: 569-574.

Munawar, M. \& I. F. Munawar, 1987. Phytoplankton bioassays for evaluating toxicity of in situ sediment contaminants. In: R. L. Thomas, R. Evans, A. Hamilton, M. Munawar, T. Reynoldsen \& H. Sadar (Eds.) Ecological effects of in situ sediment contaminants. Hydrobiologia. 149: 87-105.

Ongley, E. D., D. A. Birkholz, J. H. Carey \& M. R. Samoiloff, 1988. Is water a relevant sampling medium for toxic chemicals? An alternative environmental sensing strategy. J. Envir. Qual. 17: 391-401.

Thomas, J. M. \& J. F. Cline, 1985. Modification of the Neubauer technique to assess toxicity of hazardous chemicals in soils. Envir. Toxicol. Chem. 4: 201-207.

Williams, L. G., P. M. Chapman \& T. C. Ginn, 1986. A comparative evaluation of marine sediment toxicity using bacterial luminescence, oyster embryo and amphipod sediment bioassays. Mar. Envir. Res. 19: 225-249. 